\title{
PSEUDOTUMOR ORAL FIBROSO CALCIFICANTE PÓS GRANULOMA PIOGÊNICO RECIDIVANTE
}

\author{
ORAL CALCIFYNG FIBROUS PSEUDOTUMOR \\ AFTER RECURRENT PYOGENIC GRANULOMA
}

\begin{abstract}
${ }^{1}$ Gabrielle Gava Feriani, ${ }^{1}$ Gabrielle Soares Barreto Venâncio, ${ }^{2}$ Daniel Samary Silva Lobato, ${ }^{3}$ Fernanda Luna de Azevedo

1 Acadêmicas Faculdade de Medicina de Campos

2 Professor Adjunto do Departamento de Patologia Geral da Faculdade de Medicina de Campos

3 Dentista com experiência em Odontoradiologia atuando no Centro de Saúde de Campos dos Goytacazes
\end{abstract}

Hospital Escola Álvaro Alvim - R. Barão da Lagoa Dourada, 409 - Centro, Campos Dos Goytacazes - RJ, 28035211

Gabrielle Gava Feriani

Endereço: Rua Voluntários da Pátria, número 99 - Centro.

Telefone: (28) 99973-7102 - E-mail de correspondência: ferianigabi@gmail.com

\section{RESUMO}

Pseudotumor fibroso calcificante é uma lesão rara histologicamente caracterizado por abundante tecido colagenizado com infiltrado linfoplasmocitário focal e calcificações psamomáticas e distróficas. São mais frequentes em crianças e jovens adultos. Se caracterizam como lesões clinicamente benignas que podem se formar sobre uma ampla distribuição anatômica, inclusive no subcutâneo e tecidos moles profundos, bem como na serosa e localizações viscerais. A causa e os mecanismos patológicos são desconhecidos. A excisão simples com uma margem de tecido normal é o tratamento de escolha, e o risco de recorrência é baixo. Paciente do sexo feminino, feoderma, 20 anos, queixava-se de uma dor discreta na região lingual dos incisivos inferiores, porém com grande desconforto. Ao exame clínico observou-se crescimento tecidual de consistência firme, irregular, de coloração avermelhada e com sangramento ao toque. Foi realizada biópsia da mucosa oral com laudo histopatológico compatível com pseudotumor oral fibroso calcificante. A paciente foi encaminhada para o serviço de cirurgia odontológica do Centro de Saúde da cidade de Campos dos Goytacazes para tratamento pré-

\begin{abstract}
Calcifyng Fibrous Pseudotumor is a rare lesion histologically characterized by abundant collagenized tissue with focal lymphoplasmacytic infiltrate and psamomatic and dystrophic calcifications. Are most often in children and young adults. They are characterized as clinically benign lesions that can form over a wide anatomical distribution, including in the subcutaneous and deep soft tissues, as well as in the serous and visceral locations. The cause and pathological mechanisms are unknown. Simple excision with a normal tissue margin is the treatment of choice, and the risk of recurrence is low. Female patient, brown skin, 20 years old, complained of mild pain in the lingual region of the lower incisors, but with great discomfort. On clinical examination, tissue growth of firm, irregular consistency, reddish color and bleeding to the touch was observed. A biopsy of the oral mucosa was performed with a histopathological report compatible with calcifying fibrous oral pseudotumor. The patient was referred to the dental surgery service of the Health Center in the city of Campos dos Goytacazes for preoperative treatment and subsequent complete excision of the lesion.
\end{abstract}


operatório e posterior excisão completa da lesão.

Palavras-chave: Calcificações; Fibrosos; Gestação; Granuloma Piogênico; Pseudotumor; Oral.

\section{INTRODUÇÃO}

Pseudotumor fibroso calcificante é uma distinta lesão de tecido mole caracterizada histologicamente por agregados linfoplasmocitários em um rico fundo de colágeno abundante, psamoma e calcificações distróficas. Este tumor foi reconhecido primeiramente em tecidos moles axiais periféricos. Na região da cabeça e pescoço, o local mais comum é o pescoço. ${ }^{12}$

$\mathrm{O}$ acometimento no sexo feminino é maior do que no sexo masculino em uma proporção de 1:1,27 e os picos de incidências são nas faixas etárias de 0 a 4 anos, 25 a 29 anos e 30 a 34 anos. A patogênese é diferente em cada pico de incidência, de 0 a 4 anos, há muitos indícios de que os fatores genéticos e/ou embriológicos estejam associados; de 25 a 29 anos associa-se a traumas, muitas vezes até relacionado a trauma mecânico e de 30 a 34 anos existem evidências de que o pseudotumor fibroso calcificante resulte como um estágio esclerosante tardio do tumor miofibroblático. ${ }^{2}$

O pseudotumor fibroso calcificante possui uma localização variada e pode ser encontrado como lesões solitárias ou múltiplas. Os aspectos histológicos encontrados na literatura são de que na macroscopia o pseudotumor apresenta-se como um tecido bem circunscrito, não costuma possuir cápsula, os tamanhos e diâmetros variam entre 0,1$25 \mathrm{~cm}$ e, além disso, pode infiltrar os tecidos ao redor. ${ }^{2} \mathrm{Na}$ maior parte dos casos é assintomático e o tumor é encontrado incidentalmente em algum exame de imagem. Quando possui sintomas, são bem inespecíficos como febre, falta de apetite, perda de peso, fadiga, fraqueza progressiva, entre outros. ${ }^{1,2}$

O diagnóstico baseia-se em uma avaliação completa, incluindo anamnese e exame físico e exames complementares como imagem, achados histológicos e imunológicos. A radiografia simples é importante para apontar o local exato do tumor, no ultrassom apresenta geralmente as massas circunscritas e com uma ecogenicidade variada devido as calcificações. Na tomografia
Keywords: Calcifyng; Fibrous; Pregnancy; Pyogenic Granuloma; Pseudotumor; Oral.

computadorizada existe um padrão de achado por conta das camadas de cálcio que o tumor apresenta. 2

O tratamento do pseudotumor oral fibroso calcificante é a sua excisão e o prognóstico é excelente. ${ }^{1}{ }^{2}$

Já o granuloma piogênico, é uma resposta tecidual exuberante, de natureza não neoplásica, em resposta a um trauma local. No entanto, a sua patogênese ainda não se apresenta completamente estabelecida, mas sabe-se de sua predileção pelo sexo feminino, explicada possivelmente devido aos efeitos vasculares provocados pelos hormônios femininos. Frequentemente, o granuloma piogênico desenvolve-se em mulheres gestantes, onde passa a empregar os termos, granuloma gravídico. ${ }^{3}, 4$

As lesões, em sua maioria, são descritas como nódulos, de consistência macia e superfície avermelhada, e o seu tamanho pode variar de 1 a 6 $\mathrm{cm}^{4}$

Dependendo do volume, o granuloma, tende a regredir por completo, após o término da gestação. No entanto, em alguns casos, deve-se considerar a remoção cirúrgica da lesão, já que ela pode interferir na alimentação, no convívio social e matrimonial, fatores importantes para que a gestação evolua adequadamente. ${ }^{3}$

\section{OBJETIVO}

Relatar um caso de granuloma piogênico recidivante que evoluiu para pseudotumor oral fibroso calcificante, desenvolvido por uma paciente gestante visando assim elucidar e conhecer melhor a correlação entre a gestação e o surgimento do granuloma piogênico com o pseudotumor oral fibroso calcificante a partir de busca na literatura.

\section{DESCRIÇÃO DO CASO}

Paciente do sexo feminino, 20 anos, gestante, compareceu ao Centro de Saúde da cidade de Campos dos Goytacazes, queixando-se de desconforto na região lingual dos incisivos inferiores. Ao exame clinico, observou-se crescimento tecidual, 
de consistência firme, irregular, coloração avermelhada e sangramento ao toque. Paciente sem comorbidades, não faz uso de medicamentos regulares e relata não ter vícios com tabaco, álcool ou outros tipos de drogas.

Foi solicitado uma terapia periodontal prévia e posteriormente foi realizado biópsia da mucosa oral e o material para o serviço de Anatomia Patológica do Hospital Escola Álvaro Alvim (HEAA). 0 laudo histopatológico foi de pseudotumor oral fibroso calcificante.

Essa lesão é recidivante na paciente, já que havia ocorrido nas duas gestações anteriores com as mesmas características clínicas e foram realizadas, respectivamente, biópsias excisionais com diagnóstico histopatológico, em ambas, de granuloma piogênico.

Na radiografia periapical da região não é possível visualizar a lesão, mas é necessário a excisão para se ter conhecimento de acometimento do periósteo, e neste caso não ocorreu essa invasão óssea.

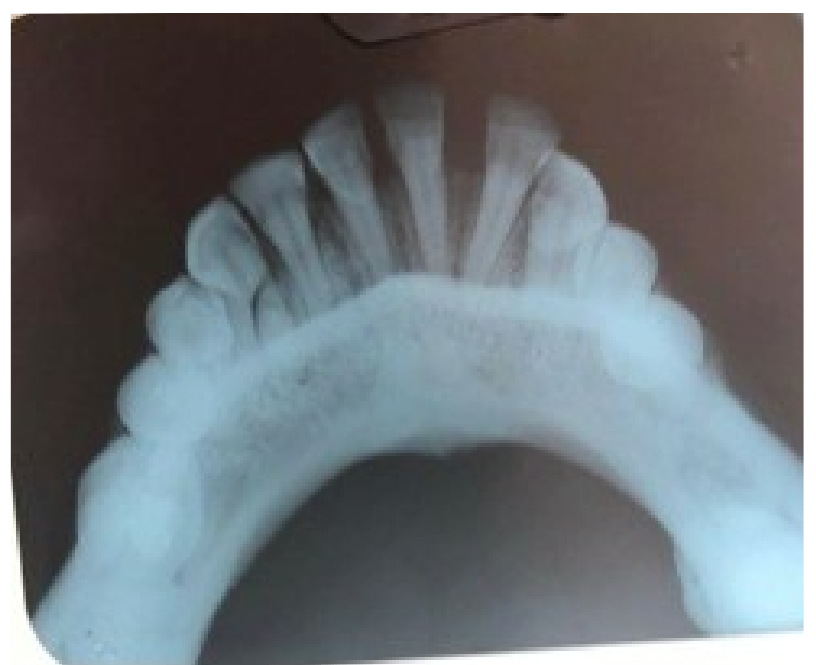

Figura 1: radiografia periapical dos incisivos inferiores

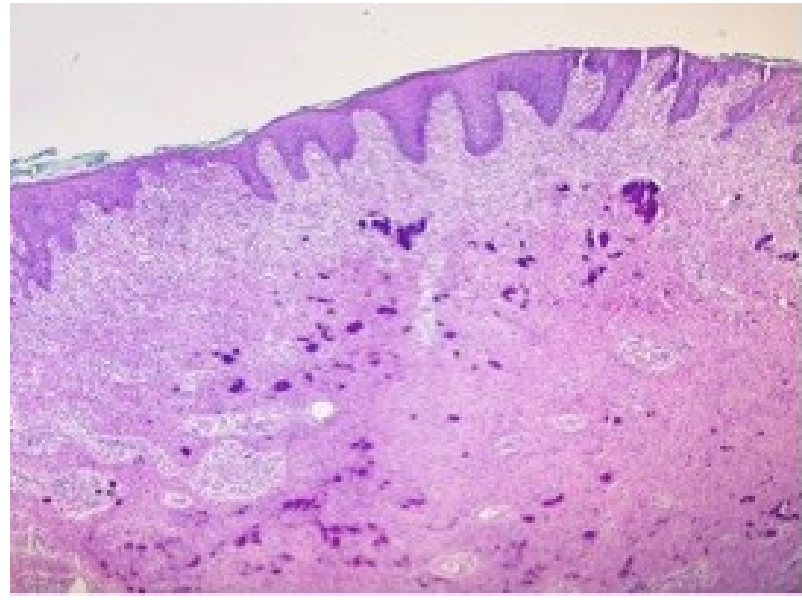

Figura 2: microscopia evidenciando formação constituída por proliferação de células fusiformes em córion, notando-se ocasional infiltrado linfoplasmocitário, áreas de deposição de colágeno denso e, de forma dispersa, focos de calcificação. Em epitélio escamoso superficial observa-se processo inflamatório crônico em atividade associado a áreas de erosão e tecido de granulação.

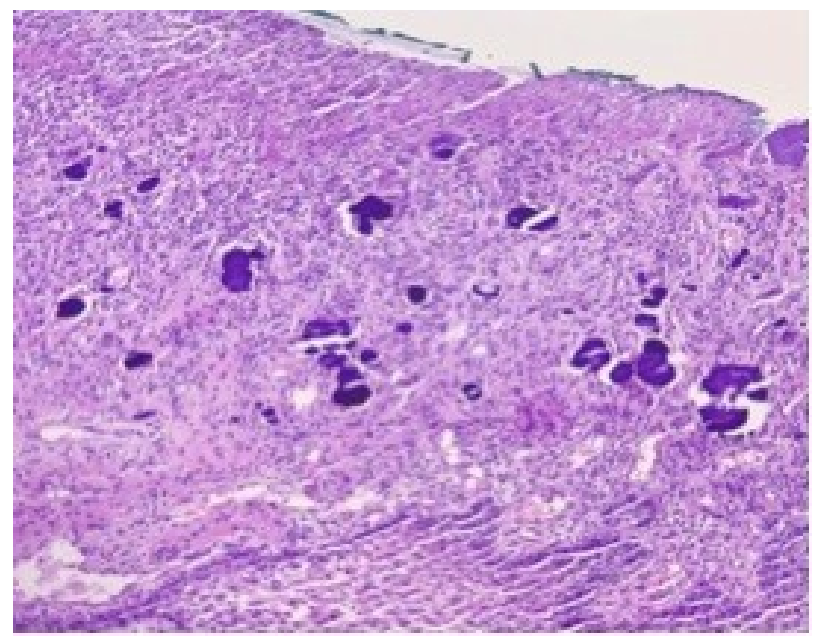

Figura 3: Área de ulceração da mucosa associada a processo inflamatório misto, notando-se focos de calcificação distrófica associada. 

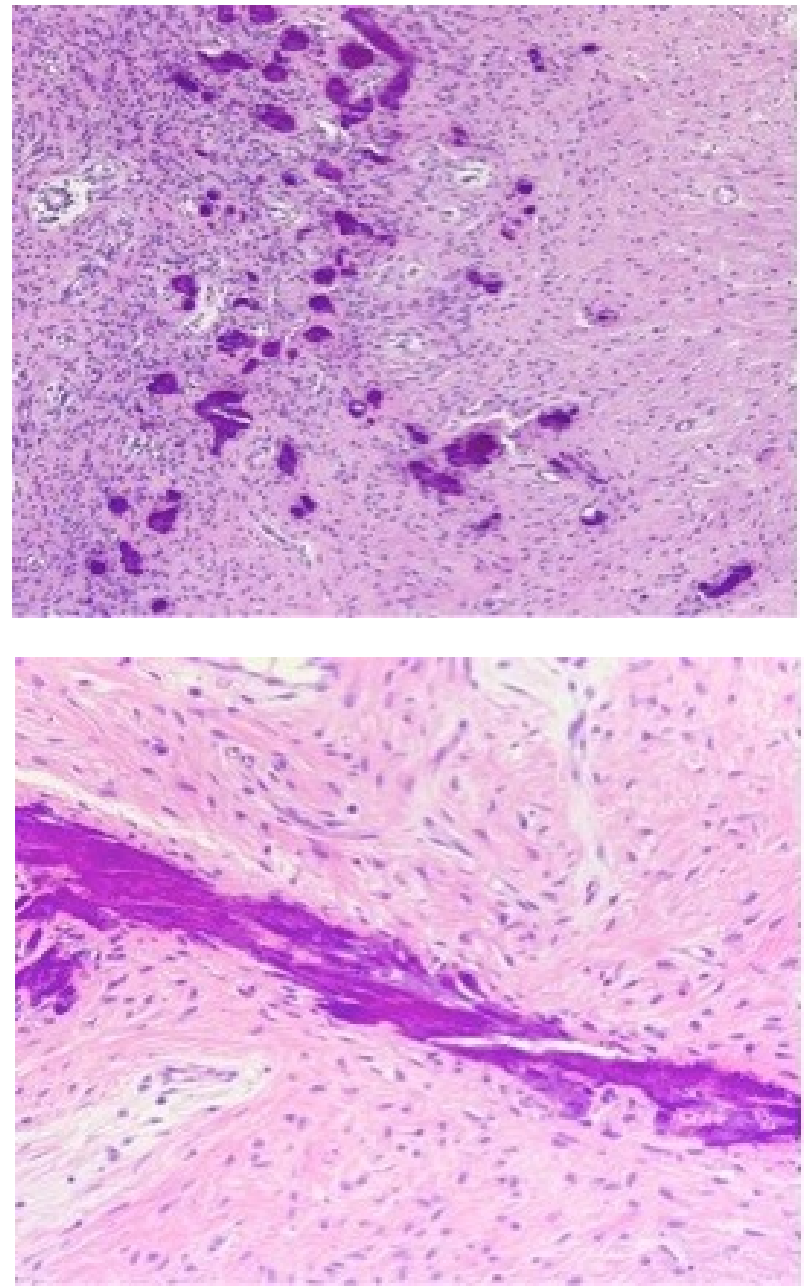

Figura 4,5: Proliferação de células fusiformes, sem atipias, exibindo focos dispersos de calcificação distrófica.

\section{DISCUSSÃO}

Tumores fibrosos calcificantes são lesões benignas raras, que mostram uma predileção para tecidos moles. Eles são caracterizados pela presença de colágeno hipocelular densamente hialinizado com psamomoma ou calcificação distrófica e infiltrado inflamatório mononuclear. ${ }^{1}$

Apresenta uma predileção feminina e podem estar localizados em vários sistemas de órgãos, mas principalmente na faixa gastrointestinal. Em relação aos achados clínicos, os pacientes portadores do pseudotumor oral fibroso calcificante são em sua maioria assintomáticos e o achado foi encontrado acidentalmente em um exame de imagem. ${ }^{1}, 2$
Quando a sintomatologia está presente, as características clínicas do pseudotumor oral fibroso calcificante são variáveis e podem ser categorizadas em dois grupos: achados agudos ou crônicos. Como condição crônica, pode ser vista uma massa visível crescente e indolor ou como uma tumoração facial, no que diz respeito às extremidades. ${ }^{2}$

O diagnóstico diferencial do pseudotumor oral fibroso calcificante depende de sua localização. Entretanto, a principal consideração no diagnóstico diferencial dos pseudotumores fibrosos calcificantes são os tumores miofibroblásticos inflamatórios, que tendem a afetar pacientes mais jovens do que os pacientes afetados pelo pseudotumor oral fibroso calcificante e apresentam como sinais e sintomas: febre, dor, perda de peso, mal estar, anemia, trombocitose, aumento da taxa de sedimentação e hipergamaglobulinemia. Além disso, podem ter lesões múltiplas, em contraste com o pseudotumor oral fibroso calcificante que pode ser assintomático e raramente é multifocal. ${ }^{2}$

O tratamento do pseudotumor oral fibroso calcificante é a sua excisão. A excisão pode ser feita de duas formas, seja por uma excisão cirúrgica aberta ou endoscópica. Porém, na maioria dos casos, são feitos a excisão aberta. Em geral, o prognóstico é excelente. ${ }^{1,2}$

Nesse caso relatado, existem vários fatores predisponentes ao desenvolvimento do granuloma piogênico, sendo eles o período gestacional e as alterações hormonais os mais importantes. Em todos os eventos o laudo histopatológico corrobora para o diagnóstico do granuloma gravídico, sendo que apenas no último evento a lesão evoluiu para o desenvolvimento de um pseudotumor oral fibroso calcificante, também com maior predileção no sexo feminino assim como o granuloma piogênico. Entretanto vale ressaltar que ainda não há uma relação bem estabelecida até o presente momento entre o pseudotumor e o granuloma piogênico, mesmo que ambos possam estar relacionados por decorrerem de traumas de repetição ou traumas antigos.

A paciente foi encaminhada ao serviço de cirurgia odontológica do Centro de Saúde da cidade de Campos dos Goytacazes-RJ e posteriormente submetida a cirurgia para tratamento do tumor, sendo que até o momento apresenta-se sem evidências da doença. 


\section{CONCLUSÕES}

Em resumo, concluímos que o tumor fibroso calcificante é uma lesão benigna caracterizada por sua grande variedade de localizações e deve ser levado em consideração no diagnóstico diferencial com diversas outras lesões, como o granuloma piogênico, comum em pacientes gestantes. Exames clínicos ou de imagem irão revelar aumento da massa incidentalmente ou após sintomatologia aguda ou crônica específica nos tumores fibrosos calcificantes, mas o diagnóstico final é feito apenas com estudos histológicos e imunohistoquímicos, já que o tumor é caracterizado por seus achados específicos nesses exames. Outros estudos devem ser realizada para a identificação da patogênese exata do tumor, como a avaliação da distribuição da idade e do sexo, já que existe uma predominância do tumor no sexo feminino.

Diante do material exposto, médicos e dentistas devem estar atentos aos sinais e sintomas de doenças malignas para proceder rapidamente com a biópsia e chegar ao diagnóstico final. Sabe-se que a realização da biópsia da lesão é determinante no diagnóstico precoce, uma vez que permite a verificação da patologia, sempre que bem indicada.

Após um exame clínico bem detalhado, foram realizados exames complementares como radiografia periapical. No entanto, o diagnóstico de pseudotumor oral fibroso calcificante apenas foi possível com a realização do exame histopatológico a partir da biopsia da lesão. Com elucidação do caso, a paciente foi logo encaminhada para tratamento com o oncologista e com o cirurgião de cabeça e pescoço.

Dessa maneira, torna-se indispensável o manejo de uma equipe multidisciplinar possibilitando o rastreio e o acompanhamento de possíveis pacientes candidatos, incluindo gestantes, que compartilham fatores de risco em comum com outros diagnósticos diferenciais do pseudotumor oral fibroso calcificante, como o granuloma piogênico, para que as condutas sejam dadas precocemente e o prognóstico possa ser melhor.

Além disso, torna-se fundamental que diante de um assunto de extrema importância para a saúde da gestante, o acompanhamento por parte dessas pacientes em centros odontológicos seja estimulado para que se garanta uma correta adequação da cavidade bucal durante a gestação, tanto no que tange a higiene bucal e dental, e na avaliação de modificações na mucosa bucal de revestimento em decorrência das alterações gerais na gravidez.

\section{REFERÊNCIAS BIBLIOGRÁFICAS}

1. BELL, Diana M.; DEKMEZIAN, Roupen H.; HUSAIN, Shaista A.; LUNA, Mario A.. Oral Calcifying Fibrous Pseudotumor: case analysis and review. Head And Neck Pathology, [S.L.], v. 2, n. 4, p. 343-347, 30 ago. 2008. Springer Science and Business Media LLC.

2. CHORTI, Angeliki et al. Calcifying Fibrous Tumor: review of 157 patients reported in international literature. Medicine: SYSTEMATIC REVIEW AND META-ANALYSIS. Tessalônica, 20 maio 2016. p. 1-12.

3. KRÜGER, Marta Silveira da Mota; ROSA, Denise Paiva da; PAPPEN, Fernanda Geraldo; ROMANO, Ana Regina; CORRêA, Fernanda de Oliveira Bello. Granuloma gravídico - relato de caso. Rev Odonto: Odontologia Clinicocientifica (online), Recife, v. 12, n. 4, p. 293-295, nov. 2013. Disponível em:

http://revodonto.bvsalud.org/scielo.php?script=sci_arttext\&pid=S1677-38882013000400011. Acesso em: 22 fev. 2021.

4. CONSOLARO, Renata Bianco et al. Granuloma Piogênico e associação com a gravidez. Revista de Odontologia da Unesp, [s. I], v. 43, n. 32, p. 0-0, maio 2014. Disponível em: https://www.revodontolunesp.com.br/article/5880198f7f8c9d0a098b51f5/pdf/rou-43-Especial5880198f7f8c9d0a098b51f5.pdf. Acesso em: 22 fev. 2021. 